\title{
Usabilidade, Design e Interface para Usuários Idosos: uma experiência em uma Casa de Apoio
}

\author{
Arthur Alexandre Artoni \\ Programa de Pós-Graduação em Ciência da Computação \\ da Universidade Estadual de Londrina \\ Londrina, Paraná - Brasil \\ arthurartoni@uel.br \\ Cinthyan Renata Sachs Camerlengo de Barbosa \\ Programa de Pós-Graduação em Ciência da Computação \\ da Universidade Estadual de Londrina \\ Londrina, Paraná - Brasil \\ cinthyan@uel.br
}

\begin{abstract}
With the growing increase in the population's life expectancy, it is natural that more and more aged people make use of technological tools. Those tools need to meet the necessities of this public that, in general, has more difficulties to deal with technologies. This paper describes the development process of a system built for a support home for elderly people and volunteers with little experience in using computerized systems. It is a technological support tool the helps the institution in a safe and reliable way. Usability problems for seniors have been minimized with specific guidelines.
\end{abstract}

\section{KEYWORDS}

Computer Systems, Ergonomics, Elderly People

\section{INTRODUÇÃO}

Vivemos em um mundo imerso em tecnologias há muito tempo e, com a crescente melhora na qualidade de vida, é notório o aumento na expectativa de vida das pessoas. Não apenas cada vez mais pessoas chegam à terceira idade, como também com uma melhor qualidade de vida [1].

Com o aumento na expectativa de vida e a diminuição no número de filhos por casal, é natural esperar um aumento na idade média da população. Esse processo acaba causando profundas mudanças na sociedade, já tendo ocorrido em vários países da Europa, e está atualmente ocorrendo em países emergentes como o Brasil [2]. Um exemplo disso é a mudança no sistema previdenciário brasileiro, aprovada em $2019^{1}$, para aumentar a idade mínima para aposentadoria. De toda forma é inegável que, cada vez mais, as pessoas idosas e/ou com pouco contato com tecnologia estão fazendo uso de sistemas tecnológicos.

Com o constante aumento desses usuários surge um novo público para a área de desenvolvimento de sistemas. O desafio agora se dá na parte de realizar da melhor maneira possível a interação entre os indivíduos e a tecnologia.

O design de interfaces é uma parte da Interação Humano Computador (IHC), responsável por melhorar a experiência do usuário durante a utilização de um software [3]. Portanto, é importante

\footnotetext{
${ }^{1}$ https://www.inss.gov.br/nova-previdencia-confira-as-principais-mudancas/
}

\author{
Bruno Carazato Oliveira \\ Programa de Pós-Graduação em Ciência da Computação \\ da Universidade Estadual de Londrina \\ Londrina, Paraná - Brasil \\ brunocarazatoo@gmail.com \\ Vanessa Tavares de Oliveira Barros \\ Programa de Pós-Graduação em Ciência da Computação \\ da Universidade Estadual de Londrina \\ Londrina, Paraná - Brasil \\ vanessa@uel.br
}

desenvolver uma interface que seja amigável também aos idosos com pouca experiência em utilização de computadores.

O trabalho tem como objetivo expor e salientar a importância de um sistema web desenvolvido para uma instituição sem fins lucrativos, cuja maior parte de seus funcionários são voluntários em idades avançadas e com pouca experiência no uso de sistemas informatizados.

Este trabalho na seção 2 apresenta a fundamentação teórica na qual o trabalho foi baseado. A seção 3 explica como era o funcionamento da casa de apoio. A seção 4 aborda os materiais e métodos que foram utilizados para criação do sistema. A seção 5 mostra a nova interface desenvolvida. Por fim, a seção 6 aponta as conclusões deste trabalho e possíveis melhorias futuras.

\section{FUNDAMENTAÇÃO TEÓRICA}

No passado, os idosos não despertavam muito interesse de diversos setores da sociedade, já que era esperada uma curta expectativa de vida desses indivíduos. Atualmente é notável o aumento da expectativa de vida das pessoas em todo planeta [4]. Em 2017, o Brasil ultrapassou a marca de 30 milhões de pessoas idosas, segundo o Instituto Brasileiro de Geografia e Estatística (IBGE) ${ }^{2}$.

O envelhecimento é um processo natural no decorrer da vida, trazendo com ele algumas consequências como: declínio de algumas funções motoras e sensoriais, diminuição da capacidade de aprendizagem devido à redução do número de neurônios e, em alguns casos, podendo desenvolver deficiências como dificuldade de enxergar, ouvir e de se locomover [5].

Pessoas da terceira idade e voluntários, que buscam aprender a participar de atividades, na maioria das vezes, estão à procura de uma forma de melhorar sua autoestima, segundo Xavier et al. [6], dando significado a sua própria existência.

No geral, as interfaces padrões dos sistemas dependem de aspectos motores, perceptivos, cognitivos e psíquicos. No caso dos idosos é bem possível que os mesmos apresentem deficiências em um ou mais desses aspectos, além de outras dificuldades de aprendizagem que ocorrem naturalmente durante o processo de envelhecimento [6].

\footnotetext{
${ }^{2}$ https://bit.ly/2xzpSK3
} 
O crescimento dessa população abriu uma nova perspectiva no que se refere à criação de produtos e serviços, e cada vez mais esses têm o foco em um segmento específico. Contudo, existem vários fatores que devem ser considerados ao desenvolver uma aplicação/interface, sendo os mais relevantes [4]: a ergonomia e a usabilidade.

Ergonomia pode ser definida como o estudo que visa melhorar a relação entre usuário e interface/aplicação [4]. Um exemplo de ergonomia é sempre manter o mesmo padrão e localização de estruturas da interface, como, por exemplo, ao usar menus na parte superior da interface. Não faz sentido que, ao abrir uma nova funcionalidade da mesma, esse menu mude de posição.

Usabilidade pode ser descrita como a facilidade com a qual o usuário interage com a interface. Em outras palavras, desenvolver um sistema que seja "autoexplicativo" e de simples utilização mesmo para usuários sem um treinamento específico [7]. Segundo Nielsen [8], para avaliar essa interação, podem ser considerados fatores como facilidade de aprendizado, rapidez e praticidade para realizar tarefas que não são executadas há algum tempo ou frequentemente utilizadas, bem como a satisfação do usuário [9].

Ao projetar um sistema que será usado em sua maioria por idosos, é fundamental levar em conta as alterações físicas que são sofridas por esse grupo. Um exemplo clássico é que, em geral, os idosos têm uma dificuldade maior em aprender e lidar com novas situações especialmente quando se trata de coisas mais complexas [4].

Outros fatores interessantes a serem considerados na construção de interfaces para pessoas idosas são fontes grandes, contraste entre as cores da interface para facilitar a leitura e a localização de botões, utilização de linguagem simples para descrever as funções e uso de cores mais amigáveis que não sejam agressivas a visão do usuário [1].

\section{A CASA DE APOIO}

O presente trabalho iniciou-se em 2013 com base em um projeto de sistema de gerência para uma instituição sem fins lucrativos, o qual será descrito neste trabalho apenas como casa de apoio. Este sistema foi pensado a fim de satisfazer as necessidades dessa instituição, que é uma casa de apoio, cujo objetivo é acolher gratuitamente pacientes e seus acompanhantes, vindos de outros municípios que estão em tratamento contra o câncer em um hospital especializado e referência para o tratamento em toda a região. Sua motivação parte em criar um ambiente acolhedor para pessoas que vêm de cidades da região em busca de tratamento, além de evitar viagens diárias e o cansaço resultante dessas.

Durante sua permanência, as pessoas atendidas recebem hospedagem, 6 refeições diárias (café da manhã, lanche, almoço, café da tarde, jantar e lanche da noite), atendimento espiritual, social e psicológico, além da acolhida de funcionários e voluntários. A instituição é administrada pelas Irmãs Claretianas com o auxílio de voluntários, totalizando 10 funcionários. A estrutura física da instituição é de $711 \mathrm{~m}^{2}$ com capacidade para 42 pessoas e 15 quartos divididos em 4 blocos, sendo eles para mulheres, homens, casais e acompanhantes.

\subsection{Gerência}

Toda parte de cadastramento dos hóspedes e acompanhantes, bem como de gerência da instituição eram feitas manualmente com uso de fichas impressas. Na Fig. 1 pode ser vista uma parte da ficha de cadastro de paciente.

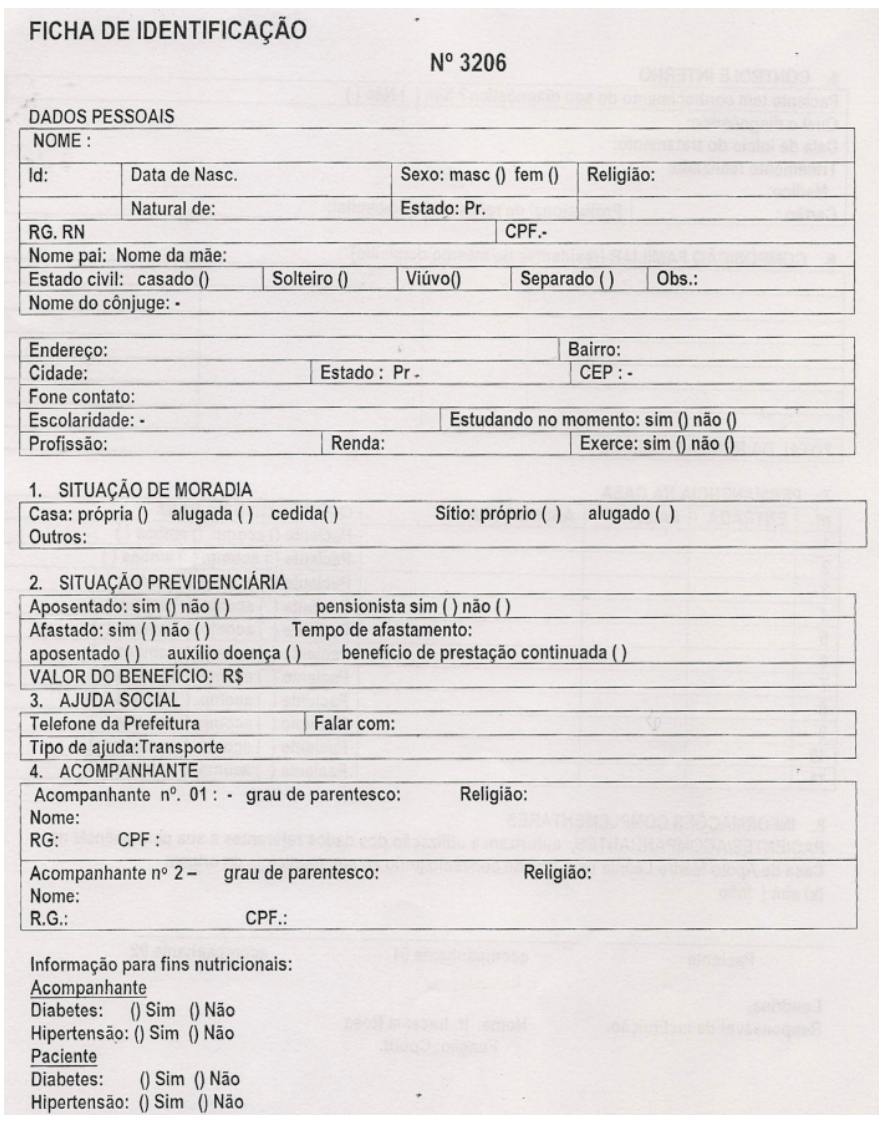

Figura 1: Uma parte da ficha de identificação de pacientes

Além das fichas de pacientes e acompanhantes, também eram usados papéis para fazer o controle das refeições servidas a esses, bem como refeições avulsas. Posteriormente, esses dados eram utilizados para prestação de contas da instituição, a qual gerava relatórios, utilizando tais fichas, para prestar contas aos municípios vizinhos, mostrando quantos pacientes de lá foram recebidos, dentre outras informações.

Devido ao crescente número de atendimentos realizados pela instituição, esse sistema manual de gerência tornou-se um problema, dificultando o trabalho burocrático da mesma. Por essa razão, a instituição procurou o Departamento de Computação da Universidade Estadual de Londrina para solicitar um software para auxiliar esse processo, esse foi desenvolvido como parte da avaliação da disciplina de Engenharia de Software.

Após uma reunião para levantar os requisitos funcionais e nãofuncionais do sistema foram elicitados os seguintes requisitos:

- Gerenciar quartos;

- Cadastro/Consulta de pacientes e acompanhantes; 
- Controle de refeições diárias de pacientes, acompanhantes e avulsas;

- Geração de relatórios diários, mensais, anuais e por cidades.

\section{MATERIAIS E MÉTODOS}

No desenvolvimento da versão inicial do sistema, a primeira etapa consistiu no levantamento dos requisitos funcionais e não-funcionais do software. Em seguida iniciou-se a etapa de diagramação e, por fim, a de codificação. Para a construção do software, as tecnologias utilizadas foram

- PHP, na versão 5.5.16;

- HTML e CSS;

- MYSQL, na versão 3.4.5.

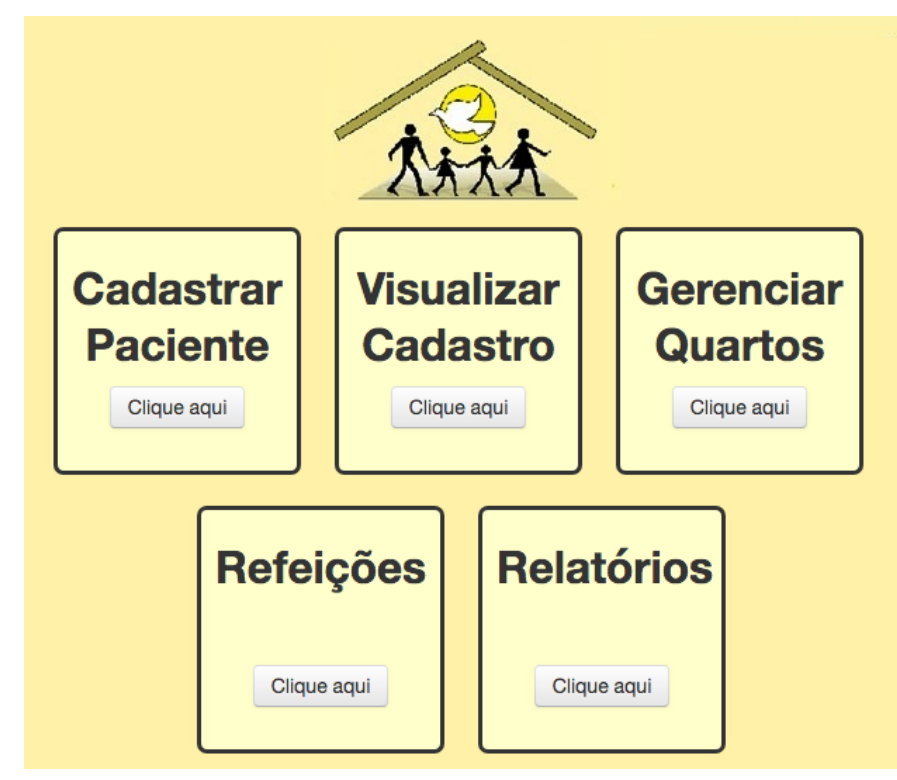

Figura 2: Tela inicial do sistema

A Fig. 3 exibe a parte do sistema referente à gestão das refeições, com a qual é possível cadastrar refeições de hóspedes e acompa-

nhantes e também refeições avulsas. elevados no futuro.

Essa primeira versão foi sem a realização de estudo envolvendo a ergonomia. Na versão inicial do sistema, as tecnologias escolhidas para o desenvolvimento do sistema foram gratuitas. Além disso, elas possuem uma maior facilidade na preparação do ambiente de desenvolvimento, um menor custo de manutenção do servidor e das necessidades de produção. Diferentemente de outras opções existentes, como por exemplo, Java Web, cujos custos do ambiente de produção, manutenção e requisitos do servidor são maiores, bem como o banco de dados Oracle, o qual exige uma licença paga para utilização.

Ainda que a versão inicial do sistema tenha sido desenvolvida sem estudos preliminares de ergonomia, a mesma foi escolhida pelos funcionários da Casa de Apoio, pois, entre as opções, também desenvolvidas pelos alunos, tal versão possuía a interface mais simples e amigável que as demais, segundo seus funcionários, o que facilitava a utilização por usuários com menos experiência no uso de computadores, o que nesse caso, foi um grande diferencial.

Com base no público alvo deste projeto, foi elaborado um questionário, com base nas heurísticas de Nielsen [8], a fim de validar a interface atual e desenvolver uma nova que oferecesse mais ergonomia aos usuários.

\subsection{Versão inicial}

A Fig. 2 mostra a tela inicial da primeira versão do sistema. Por meio dessa é possível acessar todas as funcionalidades do sistema.

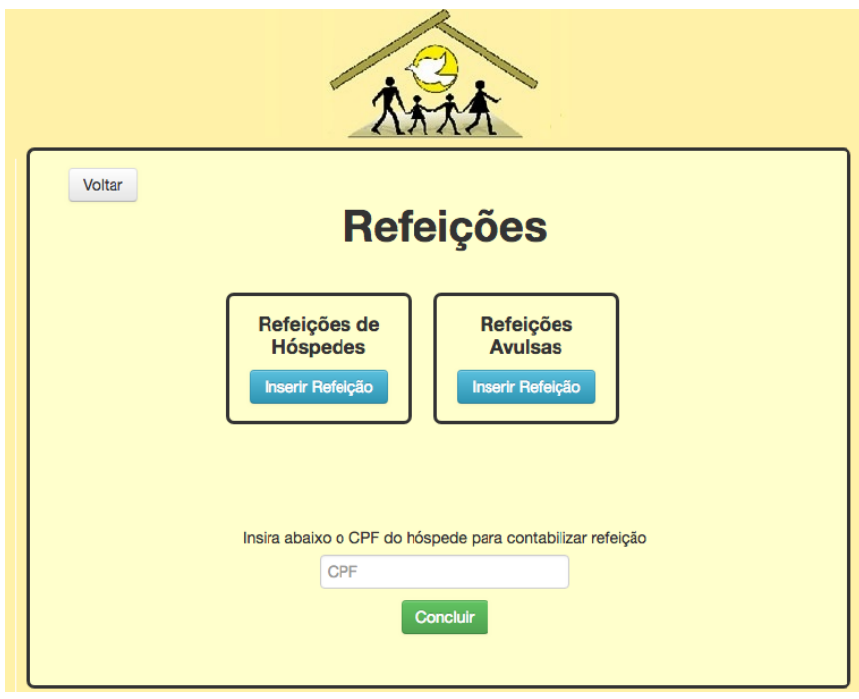

A Fig. 4 traz uma parte do formulário de cadastro de novos hóspedes e, para uma melhor visualização, a imagem foi recortada. Além da ficha de cadastro de paciente, também existe a ficha de acompanhante.
Figura 3: Gerenciamento das Refeições 


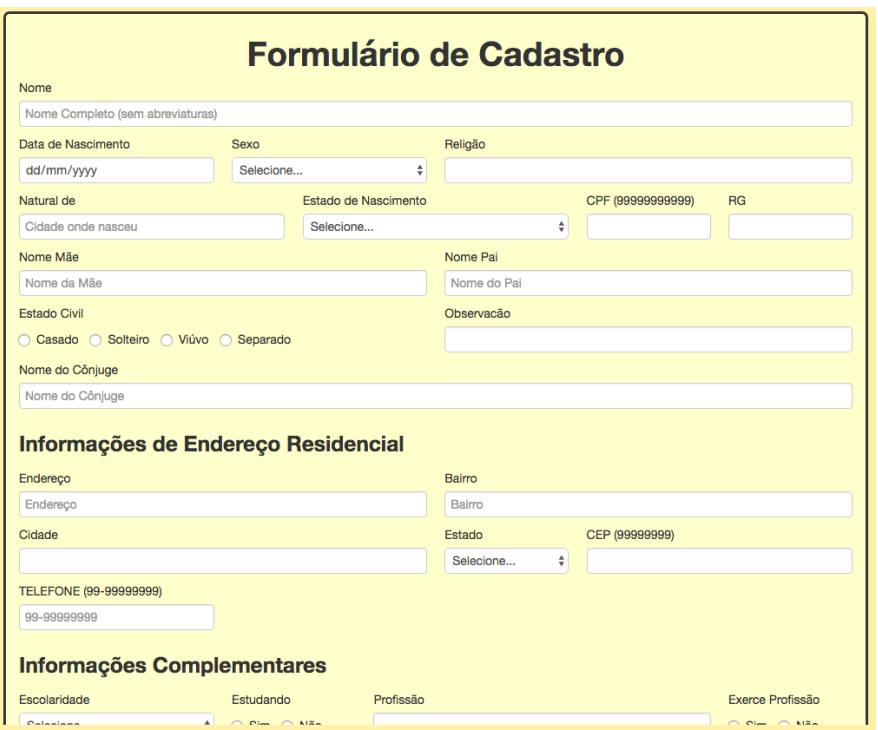

Figura 4: Formulário de Cadastro do Paciente

A Fig. 5 exibe o cadastro para o usuário. O preenchimento e a exibição desses formulários foram desenvolvidos para ter um formato parecido com a ficha de cadastro original apresentada na Fig. 1. Dessa forma, foi possível criar uma familiaridade entre o sistema e o usuário, gerando maior facilidade em lidar com o sistema.

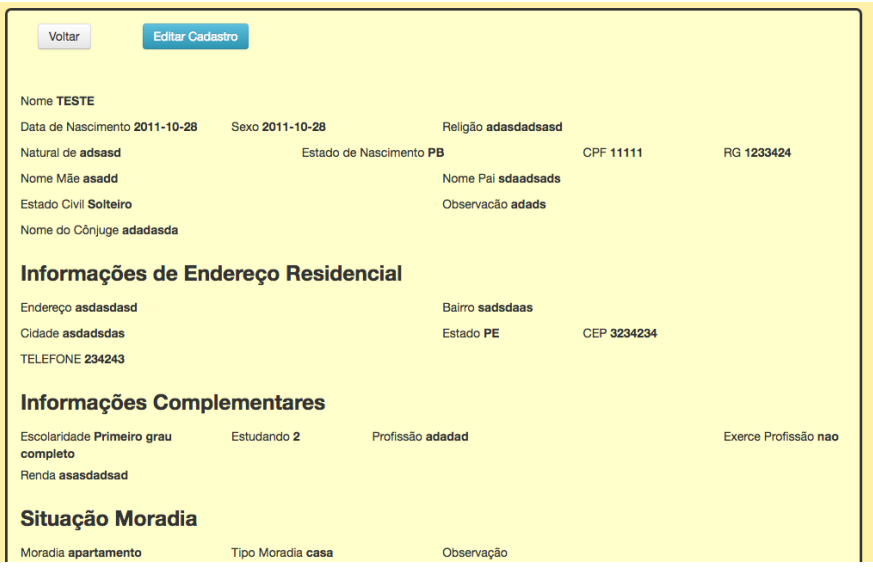

Figura 5: Formulário de Cadastro do Paciente

As Figs 6 e 7 mostram o gerenciamento de quartos. Nessa parte do sistema é possível visualizar os quartos já existentes, criar um novo quarto, editá-lo e excluí-lo. Quando há vagas disponíveis, os quartos são mostrados em verde e quando estão lotados tornam-se vermelhos.

Essa utilização foi escolhida para tornar mais rápida a adaptação com o sistema, uma vez que a utilização de cores como verde para quartos com vagas e vermelho para quartos ocupados tornaram o uso do sistema ainda mais intuitivo [10].

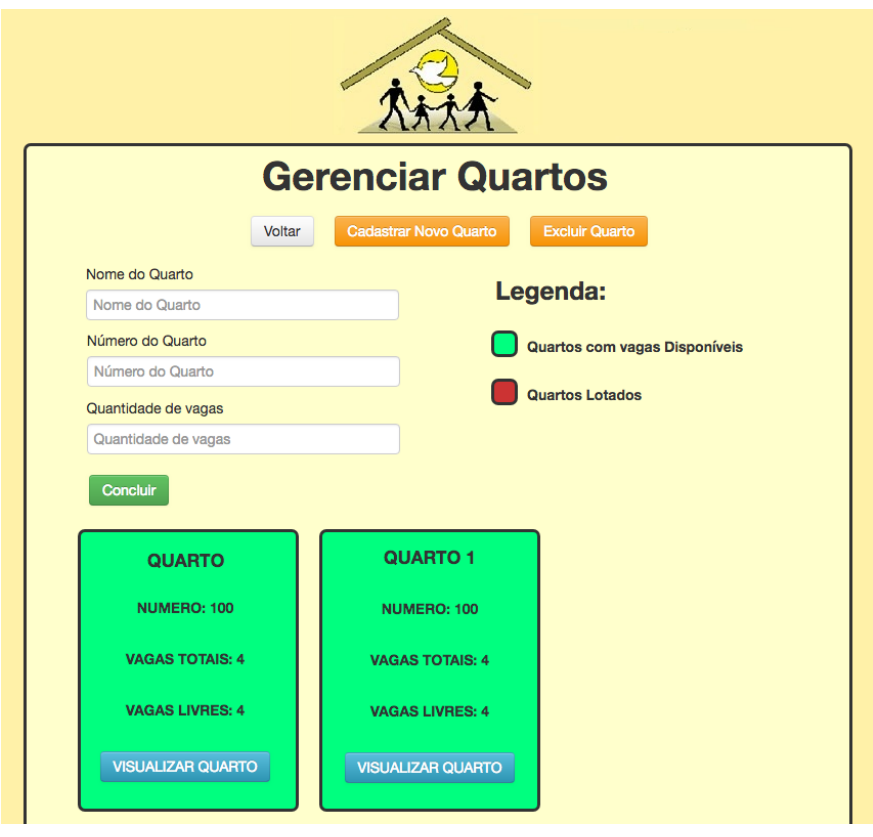

Figura 6: Interface para criação de um novo quarto

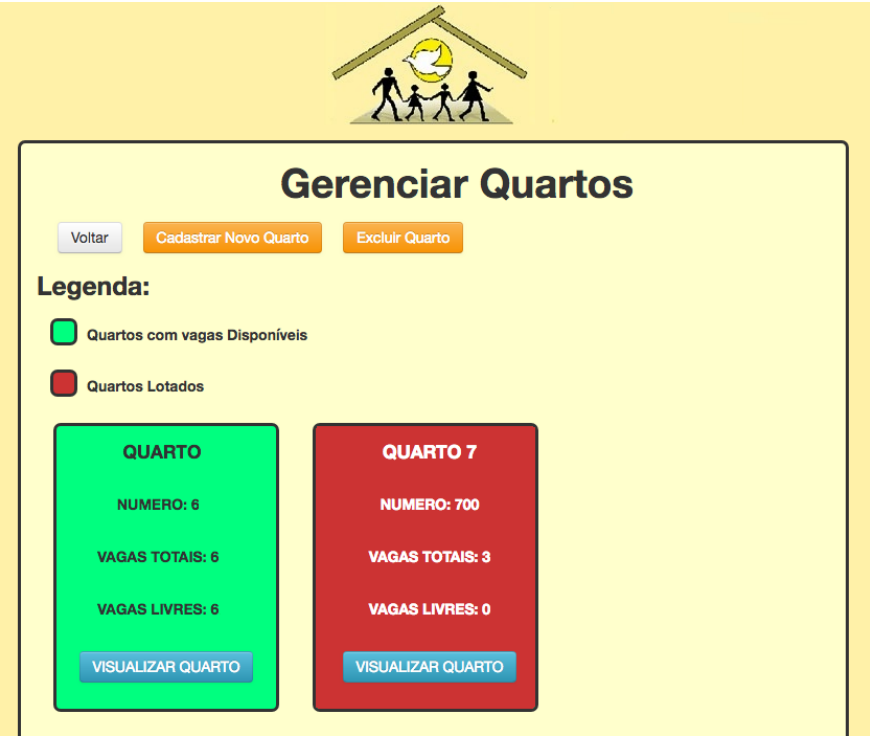

Figura 7: Visualização dos quartos já existentes

A Fig. 8 tem a página de geração de relatórios. Nela é possível gerar relatórios anuais, mensais, diários e de uma data específica. Os relatórios contêm informações referentes à contabilidade da Casa de Apoio e são gerados em formato pdf. 


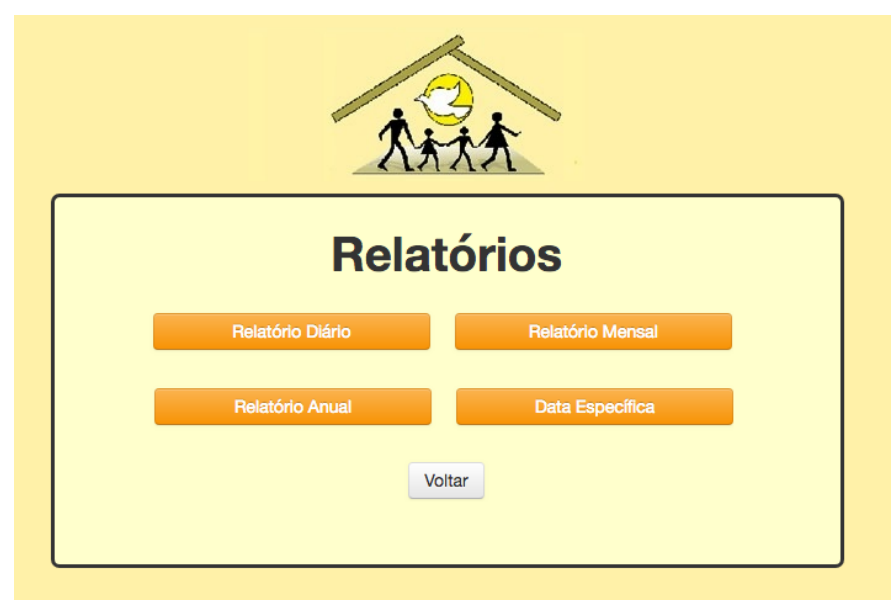

Figura 8: Geração de relatórios do sistema

\subsection{Questionário}

O seguinte questionário, baseados nas heurísticas de Nielsen [8], foi utilizado como base na criação da nova versão da interface do sistema. Cada recurso da interface foi submetido ao questionário para avaliar sua viabilidade. Esse também foi respondido por funcionários do local.

(1) O sistema é de fácil entendimento para verificar a disponibilidade das funções desejadas?

(2) O sistema possui termos de difícil compreensão?

(3) O sistema é de fácil navegação entre as funcionalidades?

(4) O sistema permite que você insira informações incorretas em campos inadequados, como por exemplo letras no campo de $\mathrm{CPF}$ ?

(5) O sistema torna necessário a memorização de informações ou elas são de fácil acesso?

(6) Você acha necessário que o sistema apresente opções para tornar mais rápido o acesso a alguma funcionalidade?

(7) Na sua opinião, na interface do sistema existem elementos desnecessários?

(8) Existem elementos que deveriam ser removidos da interface para torná-la mais agradável?

(9) Ao se deparar com algum erro, o sistema é claro sobre as causas do problema e como prosseguir após a sua ocorrência?

(10) Você acha necessário colocar algum mecanismo de ajuda para a utilização do sistema?

(11) Escolha uma opção abaixo em relação à utilização do sistema:

(a) O sistema é totalmente intuitivo e eu consegui facilmente entender qual caminho seguir até a opção desejada.

(b) O sistema em geral é intuitivo e na maioria das vezes eu consegui facilmente entender qual caminho seguir até a opção desejada.

(c) O sistema é pouco intuitivo e poucas vezes eu consegui facilmente entender qual caminho seguir até a opção desejada.

(d) O sistema em geral não é intuitivo e na maioria das vezes eu não consegui facilmente entender qual caminho seguir até a opção desejada.

\section{NOVA VERSÃO E A ERGONOMIA}

Esta seção apresenta as modificações que foram realizadas, em 2019, na interface da nova versão do sistema em relação à versão anterior.

Essa versão teve como foco a ergonomia dos usuários, ou seja, o objetivo foi tornar o sistema mais ergonômico e melhorar a produtividade e o conforto dos usuários do sistema ao trazer o foco em uma interface que proporcione uma interação produtiva e agradável.

Na Fig. 9 é mostrada a nova interface do sistema, a qual é diferente da primeira versão. O quadrado foi substituído por botões maiores que respondem ao toque mouse trocando de cor, como no botão de cadastrar novo paciente. Ícones intuitivos foram adicionados para facilitar o acesso de pessoas que têm alguma dificuldade com leitura.

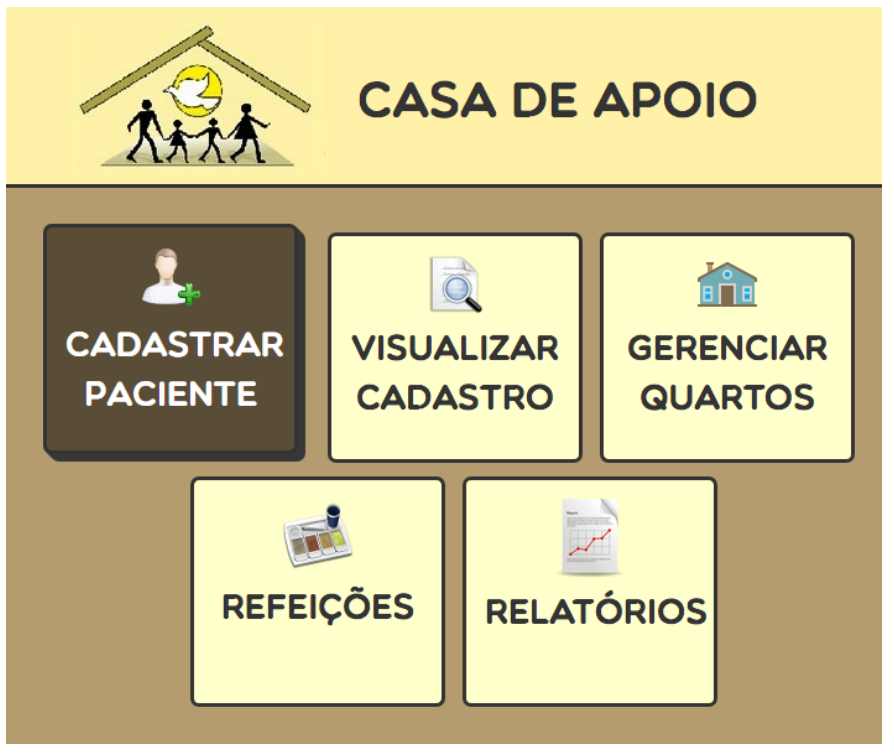

Figura 9: Tela inicial do sistema

A busca do cadastro do paciente ou acompanhante continua sendo feita com a utilização do CPF, conforme foi solicitado pelos funcionários. A interface pode ser vista na Fig. 10. Após inserir um $\mathrm{CPF}$ válido, o sistema irá retornar a ficha de cadastro correspondente.

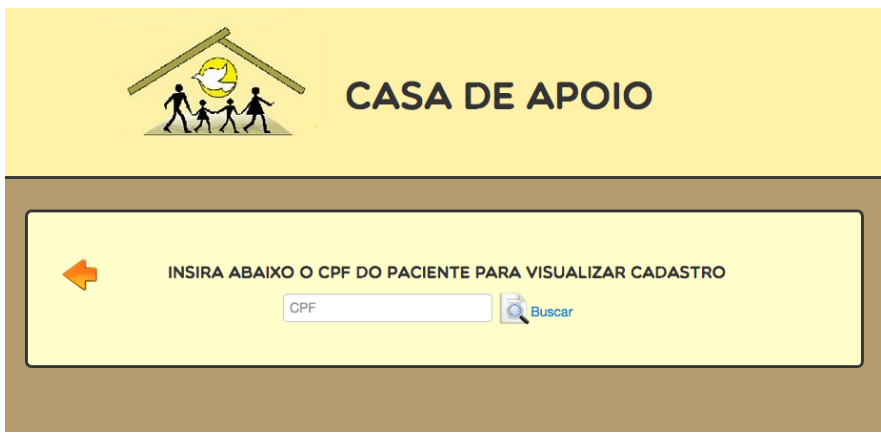

Figura 10: Busca de Cadastro de Paciente 
O cadastro e também a visualização de pacientes e acompanhantes manteve o mesmo padrão inspirado na ficha impressa usada. A mudança de cor do fundo do sistema para um tom mais escuro, como pode ser vista na Fig. 11, torna mais agradável a leitura e preenchimento de dados durante a utilização do sistema [1].

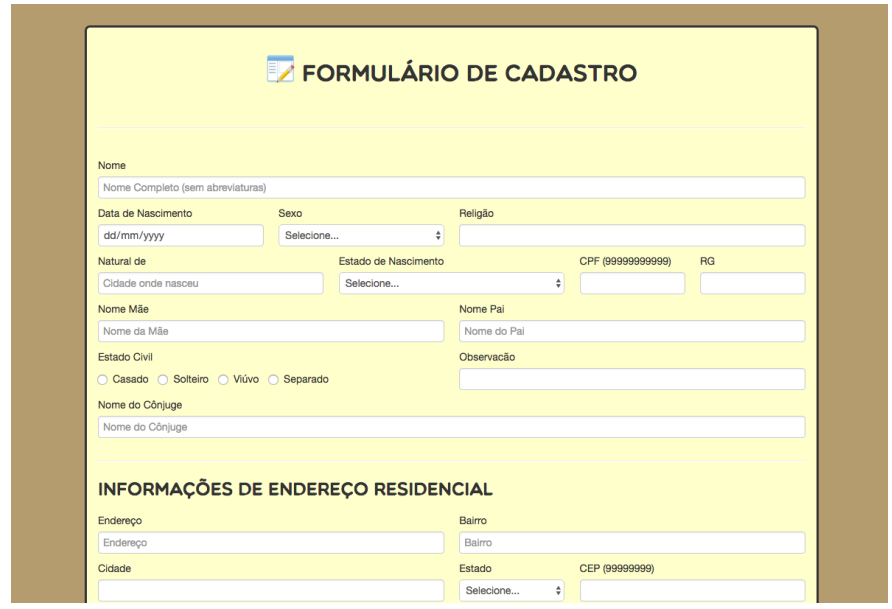

Figura 11: Formulário de Cadastro do Paciente

O modelo de gerenciamento de refeições não sofreu nenhum tipo de alteração, além das estéticas e cores de fundo, como pode ser visto na Fig. 12, pois não foi solicitado nenhum tipo de melhoria para essa página.

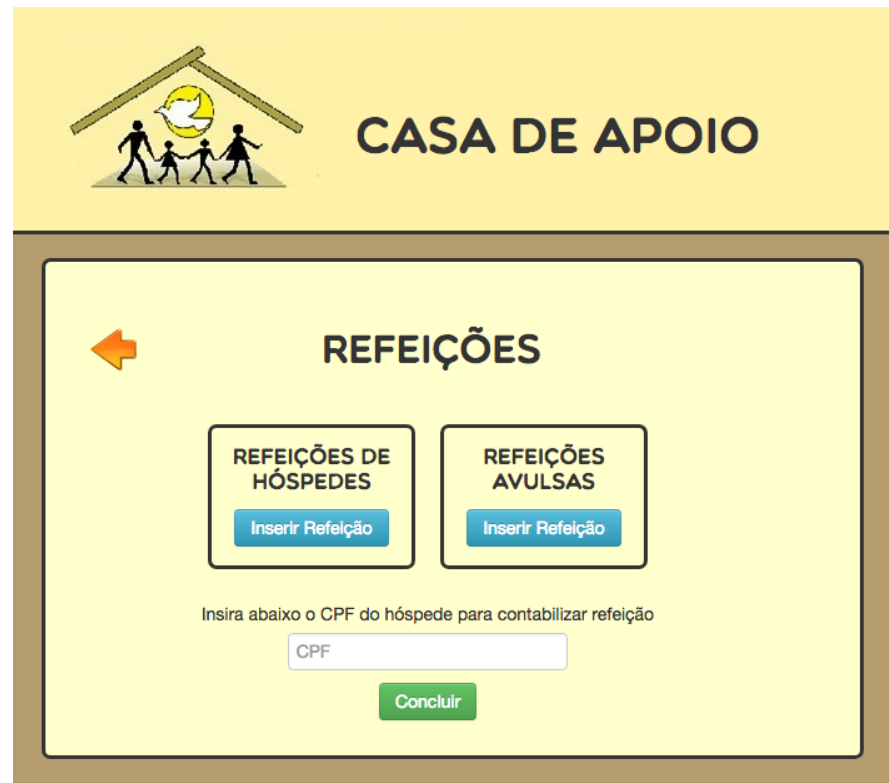

Figura 12: Gerenciamento das Refeições

A parte de gerenciamento de quartos, mostrada na Fig. 13, também sofreu apenas alterações estéticas e de cores presentes nas outras funcionalidades do projeto. O sistema de cores utilizado para mostrar as vagas nos quartos foi muito elogiado pelos usuários, na primeira versão, e portanto foi mantido na segunda.

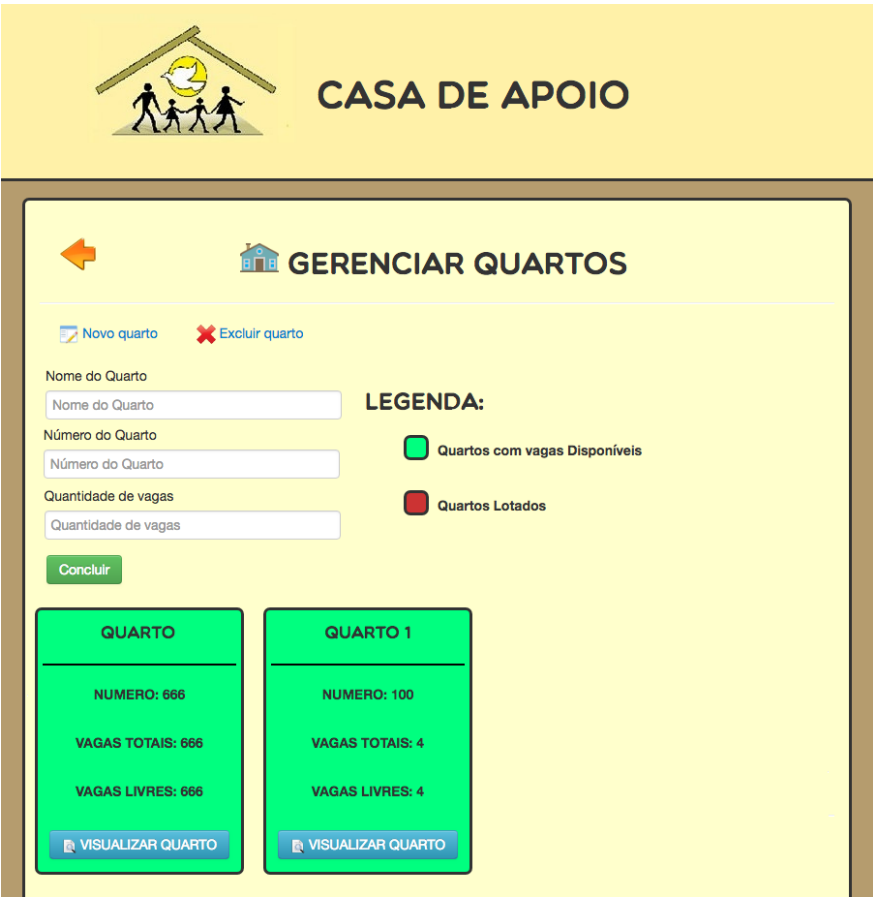

Figura 13: Gerenciamento dos Quartos

O gerenciamento de relatórios, exibido na Fig. 14, também teve boa aceitação por sua simplicidade e facilidade de uso. Portanto, assim como outras partes do sistema, sofreu apenas alterações estéticas e de cores.

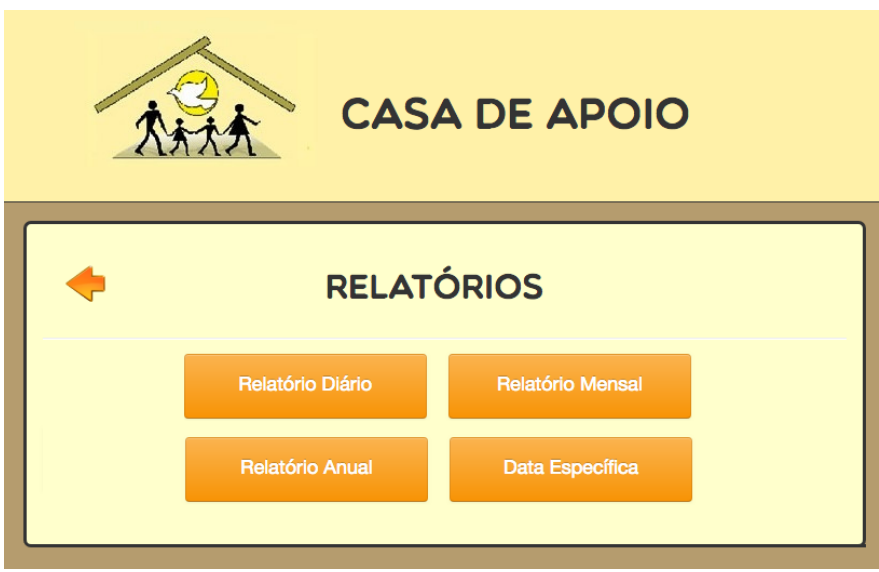

Figura 14: Geração de relatórios do sistema

A nova interface manteve os tons pastéis como paleta de cores da primeira versão, que foi bem aceita pelos usuários, porém o novo fundo das páginas recebe uma cor mais escura para manter um contraste forte em relação ao texto, diferenciando melhor os elementos 
da página, e também pelo texto possuir uma fonte maior, pois segundo Mol et al. [1], o design adequado para atender às necessidades das pessoas mais velhas deve seguir essas características.

Para Pedrassolli e Neris [10], uma das características mais importantes de uma interface é o uso correto da cor, uma vez que ao ser vista e interpretada pelo cérebro, a mesma exerce uma forte influência sobre as sensações e emoções do usuário. Como a antiga palheta de cores do sistema já havia agradado o público alvo, ela foi mantida em partes do sistema. Algumas outras cores foram adicionadas a fim de melhorar a experiência do usuário.

Além da modificação das cores, também foram adicionados imagens (ícones) no menu da tela inicial, ao invés de somente texto, assim, cria-se uma maior facilidade para aprender a interagir com a interface do sistema [1].

\section{RESULTADOS}

A primeira versão do sistema foi implantada na Casa de Apoio, cumprindo a princípio todas as expectativas da instituição. Apesar de gerar um primeiro feedback positivo, existia a necessidade de realizar um estudo sobre ergonomia e usabilidade, a fim de tornar o sistema melhor para os usuários. Dessa forma, utilizando as heurísticas de Nielsen [8] e os pontos abordados no questionário, desenvolveu-se uma nova versão da interface do sistema.

Essa nova versão manteve as funcionalidades e características, que fizeram com que a primeira versão do sistema fosse escolhida. Porém, na versão inicial havia muitas funções na mesma tela, ícones grandes e semelhança com as antigas fichas impressas utilizadas. Essas funcionalidades foram melhoradas utilizando os conceitos de usabilidade e de ergonomia, conseguindo criar um sistema que mantém a simplicidade e também apresentando uma interface mais amigável, ou seja tendo a habilidade de reagir como esperado pelo usuário.

\section{CONCLUSÕES}

A versão inicial do sistema que foi desenvolvida conseguiu atender as necessidades gerenciais da instituição. A interface da primeira versão, ainda que simples e considerada não tão estética por outros grupos etários e usuários com maior experiência no uso de sistemas computadorizados, foi bem aceita pelo público de idades mais avançadas, uma vez que mantém aspectos semelhantes aos processos anteriormente utilizados.

Além do sistema descrito neste trabalho, outros que atendiam os mesmos requisitos também foram apresentados para tal público e não foram bem aceitos. Esses, em sua maioria, possuíam interfaces mais tradicionais com design responsivo, utilizando frameworks, Bootstrap que geravam interfaces com muitas barras, informações e botões de acesso que, diferente do desenvolvido neste trabalho, utilizavam apenas ícones e não textos. Isso apesar de agradar os usuários mais experientes, podem confundir os mais idosos e inexperientes.

Este recente projeto buscou simplificar e refinar a interface inicial do sistema que já havia tido uma boa aceitação pelos usuários. Para a melhoria e simplificação foram feitas aplicações de conceitos de ergonomia, usabilidade e heurísticas de Nielsen [8] mantendo todas as características e funcionalidades necessárias para a Casa de Apoio.
Como trabalhos futuros pretende-se analisar como os usuários idosos e/ou com pouca experiência na utilização de sistemas computacionais, irão se adaptar à nova interface proposta com o passar do tempo.

\section{REFERÊNCIAS}

[1] Artur Martins Mol and Lucila Ishitani. Avaliação de interface de um aplicativo para uso em telefone celular e voltado para a terceira idade. In Proceedings of the IX Symposium on Human Factors in Computing Systems, IHC '10, page 1-10. Sociedade Brasileira de Computação, 2010.

[2] Elisa Nakagawa, Pablo Oliveira Antonino, Martin Becker, José Maldonado, Holger Storf, Karina Villela, and Dieter Rombach. Relevance and perspectives of AAL in Brazil. Journal of Systems and Software, 86:985-996, 2013. doi: 10.1016/j.jss.2012. 10.013.

[3] Rodolfo Dalla Costa and Sílvia C Matos Soares. Acessibilidade para idosos: uma abordagem inclusiva para design de interfaces. Brazilian Technology Symposium, 1, 2016. ISSN 2447-8326.

[4] Josiane Vieira Campos, Thaiana Pereira Anjos, Leila Amaral Gontijo, and Milton Luiz Horn Vieira. A usabilidade e acessibilidade de um ambiente virtual de aprendizagem com foco no usuário idoso: uma verificação ergonômica do moodle. AtoZ: novas práticas em informação e conhecimento, 4(1):10-23, 2015.

[5] Márcia Barros Sales and Walter Abrewu and Cybis. Desenvolvimento de um checklist para a avaliação de acessibilidade da Web para usuários idosos. II Seminário Acessibilidade, TI e Inclusão Digital, 2003.

[6] André J Xavier, André Luís Alice Raabe, MB Sales, and Daniel Sigulem. Desafios de interação e acessibilidade para o usuário idoso. In CBIS'2004-IX Congresso Brasileiro de Informática em Saúde, Florianópolis, 2004.

[7] Tomayess Issa and Andrew Turk. Applying usability and HCI principles in developing marketing websites. International fournal of Computer Information Systems and Industrial Management Applications, 4:76-82, 2012.

[8] Jakob Nielsen. Usability engineering. Elsevier, 1994.

[9] Marco Winckler and Marcelo Soares Pimenta. Avaliação de usabilidade de sites web. Escola Regional de Informática, pages 85-137, 2002.

[10] Leandro Carlos Pedrassolli and Vânia Paula de Almeida Néris. O uso de cores em aplicações web: um estudo dos projetos desenvolvidos no curso lato sensu de desenvolvimento de software para a web. Revista TIS, 3(2):204-214, 2014. 